Dtsch Z Akupunkt 2018 $\cdot 61: 298$

https://doi.org/10.1007/s42212-018-0119-7

() Springer Medizin Verlag GmbH, ein Teil von Springer Nature 2018

i] SACAM

\section{Kurs- und Kongressvorschau für die Schweiz}

\section{Kurse der Schweizerischen Ärztegesellschaft für Akupunktur - Chinesische Medizin - Aurikulomedizin}

\section{Kursbeginn August 2018}

25.08.2018-29.06.2019 Lehrgang Chinesische Arzneien: Differential-Diagnose (Fortgeschrittene)

Wochenend-Kurs/Einzelseminare

Zürich/Bern

\section{Kursbeginn September 2018}

09.09.2018-08.06.2019 Basis Modul Chinesische Arzneitherapie Wochenend-Kurs

20.09.2018-08.06.2019

Basis Modul Allgemeine Grundlagen

\section{Kursbeginn Oktober 2018}

19.10.2018-08.06.2019 Basis Modul Ohrakupunktur/RAC 1kontrollierte Akupunktur

Zürich/Biel

\section{Kursbeginn November 2018}

10.11.2018

Unikurs Ohrakupunktur/RAC-kontrollierte Akupunktur 2: Stufe 3a

29.11.2018-01.12.2018

ASA TCM-Kongress 2018

\section{Kursbeginn Februar 2019}

17.02.-22.02.2019

Expertenkurs Davos: Davos

Ohrakupunktur/Aurikulomedizin der

5. und 6. Stufe und klassische Akupunktur

\section{Kursbeginn März 2019}

08.03.2019-16.03.2019 Unikurs Ohrakupunktur/RAC-kontrollierte Akupunktur 2: Stufe 4

Bern/Biel

\section{Kursbeginn Juni 2019}

08.06.2019

ASA-Modulprüfungen

Bern

\section{Kursbeginn November 2019}

02.11.2019

Dem Krebs auf der Spur - die Linie der Tumore 08.11.2019-23.11.2019 $\begin{aligned} & \text { Unikurs Ohrakupunktur/RAC-kontrollierte } \\ & \text { Akupunktur 2: Stufe } 5\end{aligned}$

\section{Kursbeginn März 2020}

06.03.2020-14.03.2020

Unikurs Ohrakupunktur/RAC-kontrollierte Akupunktur 2: Stufe 6
Zürich/Bern

Zürich/Bern
Solothurn

\section{Zürich}

Bern/Biel
Schweizerische Gesellschaft für Akupuntur,

Chinesische Medizin und Auriculomedizin

Postfach 8021 ZÜRICH

Tel.: 0844200200

Fax 0313324112

E-Mail:info@sacam.ch

\section{Kursbeginn Juni 2020}

05.06.2020-06.06.2020 Unikurs Ohrakupunktur/RAC-kontrollierte

(Terminänderungen vorbehalten) Akupunktur 2: Prüfungsvorbereitung Bern

Weitere Informationen entnehmen Sie bitte den Ausschreibungen auf der Homepage der sacam: www.sacam.ch - Ärztebereich - Weiterund Fortbildung

Geschäftsstelle: SACAM, Postfach, 8021 Zürich, Tel. +41 844200 200, Fax +41313324112

Email: info@sacam.ch, www.sacam.ch 